\title{
Public Building Supervisors' Assessment of Site Progress Record Keeping Practices in Abuja, Nigeria
}

\author{
Ikemefuna Mbamali $^{1}$, Eyitene Aina Nesiama ${ }^{2}$ and Ibrahim Khalilullahi Zubairu ${ }^{1}$ \\ 1. Department of Building, Ahmadu BelloUniversity, Zaria, Nigeria \\ 2. Federal Housing Authority (FHA), Abuja, Nigeria
}

\begin{abstract}
The importance of good site progress records in quality assurance; tracking project progress; preparing, analyzing and resolving claims; and placing responsibilities in the event of dispute in building contracts is widely recognized. This study engaged Public Building Supervisors in the assessment of site progress record keeping practices in Abuja. A simple structured questionnaire (which mainly assessed the nature and importance of records kept, reasons for keeping them; level of satisfaction with the current approach, challenges and practical ways of improving the practice) was administrated to a hundred of the supervisors, out of which seventy one was properly completed and returned. The results show that all five site progress documents (minutes of progress meetings, day-work sheets, photographs, weekly site records and personal site diaries) found in literature, are in use in Abuja, and have at least a high importance rating (i.e., relative importance index, $0.6 \leq$ RII $<0.8$ ). Prominent among the reasons for keeping the records are: control of ongoing work $(\mathrm{R} 11=0.83)$ data for estimating future works and terms of contract requirement (each with RII $=0.823)$. Though the present record keeping practices were largely assessed satisfactory, $95 \%$ of the Supervisors still yearned for improvement. The challenges to the current practice are consistent with those identified in literature and are: continuity consistency, legibility and accountability; in descending order of frequency of occurrence. Computerization, regular inspection of progress documents by assigned supervisors and in-house training of site staff are recommended for improving the record keeping practices.
\end{abstract}

Key words: Site progress record - keeping, site record practices in Abuja, public building supervisors.

\section{Introduction}

As with most other developing countries provision of basic infrastructure (roads, buildings, water, electrical energy etc) remains a major concern of government in Nigeria. Hence government is still the biggest client of the construction industry in Nigeria, purchasing about $70 \%$ of the industry output [1] which translates to about $50 \%$ of her expenditure Government procure buildings through outright purchase of completed buildings or by construction of new ones through direct labor, contracting or partnering. It is customary for government agencies to have in their employment, project officers or supervisors who

Corresponding author: Ikemefuna Mbamali, $\mathrm{PhD}$, professor, research fields: building services, facilities management and sustainable construction. E-mail: mbamalikem@yahoo.com. undertake the daily monitoring of the building production process,

The supervisor may be an individual or a team authorized to act on behalf of the procuring agency to ensure compliance with acceptable building production standards as specified in the contract documents. Public Building Supervisors are usually officers within grade levels 08 and 13, with appropriate qualification in Architecture, Building, Quantity surveying or Engineering, and processing a minimum of two years post qualification experience. The main task of the supervising team on a building project is that of keeping good records of what actually takes place during the construction process. These records are useful in quality assurance, finance, tracking progress, preparing, analyzing and resolving claims, and placing of responsibilities in the event of failure [2, 3].

Currently in Nigeria construction site records are mainly kept manually [4], in the form of written 
documents as opposed to the computer based information system which is the state of the art in the developed countries. The Manual hard copy site recording practice has been reported cumbersome and error prone $[4,5]$. One other persistent problem identified in construction site record keeping is that of developing the as-built actual physical progress schedule of construction scheme [6]. Generally on construction site record keeping, available research results $[4,5,7]$ indicate that the identified problems centre around accessibility, legibility, continuity and consistency.

This work evaluates the types, methods, purposes and challenges to building site record keeping, using Public Building Supervisors in Abuja the federal capital of Nigeria; with a view to establishing empirical basis for improving the practice. It is affected by literature review and field survey which employed well structured questionnaire administered to selected public building supervisors in the target area.

\section{Literature}

\subsection{Building Site Records}

Building construction sites are information intensive environments. Various construction personnel on site need large amounts of information ranging from design drawings to personal diaries to support their work [8]. A considerable volume of records are usually amassed in the course of building construction by the main parties to the project. These records cover a variety of aspects of the construction work such as: progress, finance, quality, resource utilization time and other major events of interest, and are maintained throughout the contract period $[9,10]$.

\subsubsection{Classification of Site Records}

Chikara [10] classified the set of records for a fair sized building construction project as follows:

(1) Pre - bid Documents: invitation to bid, site visit notes, photographs, minutes of pre - bid meetings, proposed schedules and project log.
(2) Bid Documents: all supporting bid calculations, quantity take offs, subcontractors and suppliers quotations, estimated productivity of labor and equipments, proposed project schedule details; written memoranda of each quotation together with date and names of all parties involved; consultants reports; the names of other bidders and their bid amounts.

(3) Pre-contract documents:- minutes of negotiation meetings minutes of qualification hearings (where applicable); job schedules; and any other new photographs or addenda

(4) Contract Documents: original contract tender documents and all subsequent revisions, instructions to contractor; contemplated change notices issued by the owner; and sub-contractor quotations, purchase orders and correspondence.

(5) Construction Documents: these include documents used and generated in the construction process. They usually include quite a long list of items such as: duplicate copy of contract tender documents, shop drawings, daily time and equipment records, daily diary, progress photographs etc. The full list is contained in Nesiama [4].

(6) Post construction documents: as built drawings; building operation and maintenance manual, maintenance schedules and records of maintenance work effected on the building.

\subsubsection{Use and Management of Site Records}

Although the extent of records required for a particular construction project will depend on the type and size, some record keeping is however required in all cases due to the following reasons $[4,11]$.

(1) Required by law

(2) Required by the term of the contract

(3) Needed to control the ongoing work

(4) Needed as data for estimating future work

(5) Needed for preserving the contractors right under the contract.

As a matter of sound administrative practice on any project, record must be kept, filed in an orderly fashion and referred to as the occasion demands. The following 
simple rules for the management of files and records were suggested by Nesiama [4]:

(1) Determine what records are to be kept and how.

(2) Once the records have been identified, ensure that they are in fact set up, maintained and used for managing the job.

(3) Review the record keeping system from time to time, because records have a habit of growing in unexpected ways.

(4) Determine the useful life of the different components and take a systematic approach to record disposal.

(5) Take steps to ensure accuracy, reliability and hence credibility.

\subsubsection{Site Progress Records}

From Scott and Assadi [12] the records that may be considered as progress records include:

(1) Site diaries;

(2) Weekly progress reports;

(3) Day-work sheets and joint records;

(4) Photographs;

(5) As - built programmes/schedules;

(6) Minutes of progress meetings.

These documents are considered legal documents that report facts on the job site and are thus crucial for analyzing claims, resolving construction disputes and placing responsibilities as appropriate [3, 13].

\subsubsection{Challenges to Site Record Keeping}

It has been observed that progress records are often inadequate to give a full and exact picture of happenings on site [2]. The major limitations are found to revolve around

(1) Accessibility: The information is available but difficult to access or call up, due to the way it has been recorded. The major issues under this category include: lack of meaningful headings and failure to relate work done to the programme of activities.

(2) Legibility: The records are difficult to understand due to poor handwriting.

(3) Continuity: Gaps exist in the information for example, some days are blank or some events are not recorded.
(4) Consistency: Record of the same events kept by two or more record-keepers do not agree.

\subsubsection{Innovations in Site Record Keeping}

The rapid growth in information technology (IT) has impacted greatly on business systems and processes, including construction site record keeping. Computer based information systems are available today which can enable real time data flow to and from construction work sites [8]. Mobile computing hardwares are available in many shapes and sizes; there are Personal Digital Assistants (PDAs), Pen Tablets, Handheld and even PDAs combined with mobile phones [14].

Tarek et al. (2005) identified site diaries as the most important source of material on the progress of work and opined that improvement on them would lead to an improvement in site record keeping. Various types of computerized diaries currently exist in software market and include the following:

(1) Lotus Organizer. Developed by the Lotus Corporation [2].

(2) The intelligent Bar Chart for recording daily site data and automatically generating accurate "as-built" schedules that suit delay analysis [13].

(3) Various versions of window application efforts toward automating and simplifying site data recording based on Bar charts [13].

\subsection{Building Site Supervisors}

Building construction projects are usually supervised by two separate teams: the client's team and the contractor's $[4,10]$. Although their roles differ, the supervision teams have the common goal of completing the project within time and cost schedules and to quality specifications. Under the Joint Contracts Tribunal (JCT) 1998, supervision is mandatory for the contractor who is bound to deliver the project to time and cost schedules and quality specifications [4]. On the clients side site supervisors, clerk of works, site inspectors, building quality officers or building officers monitor the work or the contract. In the guidelines of duties for public servants published by the Federal 
Ministry of Establishment, building, architecture and engineering personnels within grade levels 8 and 13, have supervision and monitoring of government projects under construction, as part of their schedules.

\section{Field Survey}

A survey of progress site record-keeping practices in Abuja was carried out by means of a well structured questionnaire. The major issues addressed in the survey include: types and importance of site progress documents, reasons for keeping the records, the current approaches and benchmarks in site record keeping; and challenges to site record keeping.

One hundred (100) questionnaires were distributed to Public Building Supervisions in Abuja. Seventy one (71) were properly completed and returned, representing a response rate of $71 \%$.

\subsection{Data Analysis Procedure}

Most of the questions in the questionnaire involve assessing some aspect of site progress record - keeping on a four (4) point Likert's scale. The data analysis therefore employed the following steps.

(1) Computation of the mean using the weighted average formula

$$
\bar{x}=\frac{\Sigma f x}{\Sigma f}
$$

Where: $\bar{x}=$ mean

$\mathrm{x}=$ points on the Likert's scale $(1,2,3$, and 4$)$

$\mathrm{f}=$ frequency of respondents' choice of each point on the scale.

(2) Computation of the relative importance index (RII) for each item of interest, using the formula

$$
\begin{aligned}
\mathrm{RII} & =\frac{\Sigma f x}{\Sigma f} \cdot 1 / k \\
& =\frac{\bar{x}}{k}
\end{aligned}
$$

Where $\mathrm{k}=$ maximum point on the Likert's scale (in this case, $k=4$ ).
(3) Ranking of the items under consideration based on their RII values. The item with the highest RII value is ranked first (1) the next (2) and so on.

(4) Interpretation of the RII values as follows:

$\mathrm{RII}<0.60$, item is assessed to have low rating

$0.60 \leq \mathrm{RII}<0.80$, item assessed to have high rating.

$\mathrm{RII} \geq 0.80$ item assessed to have very high rating.

\section{Data Presentation, Analysis and Discusion of Results}

\subsection{Data Presentation and Analysis}

Data from the field survey are presented in Tables $1-5$ together with result of the analyses.

\subsection{Discussion of Results}

Table 1, present an assessment of the importance of site progress documents as a tool for monitoring and reporting progress of work on building construction sites. Except for personal site diaries with RII $=0.71$ (which implies high important rating) all the other four documents have RII $\geq 0.80$; which implies very high importance rating. Minutes of progress meetings however ranked first implying that public building supervisors see progress meetings as highest opportunity for updating their knowledge of the project and for reporting their observations.

On reason for keeping site records, Table 2 shows that all the five reasons evaluated have either high or very high RII rating. "Required for control of on going work" however ranked first while "required by the terms of contract" and "Data for estimating future work" tied on the second ranking position. It can therefore be seen that building supervisors agree that there are very good reasons for site record keeping.

Table 3 presents an assessment of building supervisors' satisfaction with current site record keeping approaches. The four criteria used are: obtaining information as needed, level of details in records, relevance of records and usefulness of the records. All four have high RII ratings meaning that the building supervisors are highly satisfied with the 
current approach to site record keeping. Table 5 however shows that $95 \%$ of them would still want an improvement in the current approach. Out of the $95 \%$, $38 \%$ favor computerization.
Table 4 assessed the frequencies with which site building supervisors experience problems of legibility, accessibility, continuity and consistency in site records. Continuity ranked highest with RII of 0.71 followed

Table 1 Nature and importance of site progress documents.

\begin{tabular}{|c|c|c|c|c|c|c|c|c|c|}
\hline \multirow{2}{*}{$\mathrm{S} / \mathrm{N}$} & & \multicolumn{4}{|c|}{ Rating $\mathrm{x} /$ response frequency (f) } & \multirow[t]{2}{*}{$\sum \mathrm{f}$} & \multirow[t]{2}{*}{ Mean } & \multirow[t]{2}{*}{ RII } & \multirow[t]{2}{*}{ Rank } \\
\hline & & 1 & 2 & 3 & 4 & & & & \\
\hline 1. & Minutes of progress & 3 & 2 & 24 & 42 & 71 & 3.51 & 0.87 & 1 \\
\hline 2. & Day work sheets and agreed records & 2 & 12 & 26 & 31 & 71 & 3.21 & 0.80 & 4 \\
\hline 3. & Photograph & 2 & 5 & 36 & 28 & 71 & 3.27 & 0.82 & 3 \\
\hline 4. & Weekly progress records & 5 & 3 & 23 & 40 & 71 & 3.38 & 0.85 & 2 \\
\hline 5. & Personal site diaries & 5 & 17 & 23 & 26 & 71 & 2.85 & 0.71 & 5 \\
\hline
\end{tabular}

Table 2 Reasons for keeping site records.

\begin{tabular}{|c|c|c|c|c|c|c|c|c|c|}
\hline \multirow{2}{*}{$\mathrm{S} / \mathrm{No}$} & \multirow{2}{*}{ Types of Documents } & \multicolumn{4}{|c|}{ Ratings (x)/Response frequency (f) } & \multirow{2}{*}{$\sum \mathrm{f}$} & \multirow{2}{*}{ Means } & \multirow{2}{*}{ RII } & \multirow{2}{*}{ Rank } \\
\hline & & 1 & 2 & 3 & 4 & & & & \\
\hline 1. & Required by law & 5 & 11 & 26 & 29 & 71 & 3.11 & 0.78 & 5 \\
\hline 2. & Required by the terms of contract & 3 & 7 & 26 & 35 & 71 & 3.31 & 0.83 & 2 \\
\hline 3. & For control of ongoing work & 1 & 5 & 28 & 37 & 71 & 3.42 & 0.86 & 1 \\
\hline 4. & Data for estimating future work & 1 & 7 & 33 & 30 & 71 & 3.30 & 0.83 & 2 \\
\hline 5. & For preserving contractors right & 3 & 15 & 22 & 31 & 71 & 3.14 & 0.79 & 4 \\
\hline
\end{tabular}

Table 3 Satisfaction with current approach to record keeping.

\begin{tabular}{|c|c|c|c|c|c|c|c|c|c|}
\hline \multirow{2}{*}{$\mathrm{S} / \mathrm{N}$} & \multirow{2}{*}{ Function } & \multicolumn{4}{|c|}{ Ratings (x) and Frequency } & \multirow{2}{*}{$\sum \mathrm{f}$} & \multirow{2}{*}{ Means } & \multirow{2}{*}{ RII } & \multirow{2}{*}{ Rank } \\
\hline & & 1 & 2 & 3 & 4 & & & & \\
\hline 1. & Obtaining information as needed & 3 & 20 & 34 & 14 & 71 & 2.83 & 0.71 & 3 \\
\hline 2. & Level of details in records & 3 & 25 & 33 & 10 & 71 & 2.70 & 0.68 & 4 \\
\hline 3. & Relevance of records & 2 & 9 & 36 & 24 & 71 & 3.15 & 0.79 & 1 \\
\hline 4. & Usefulness of records & 3 & 10 & 31 & 27 & 71 & 3.11 & 0.78 & 2 \\
\hline
\end{tabular}

Table 4 Frequency of experiencing identified challenges in use of site diaries.

\begin{tabular}{|c|c|c|c|c|c|c|c|c|c|c|}
\hline \multirow{2}{*}{$\mathrm{S} / \mathrm{N}$} & \multirow{2}{*}{ Problem Area } & \multicolumn{5}{|c|}{ Weighting (x) Responses frequency } & \multirow{2}{*}{$\sum \mathrm{f}$} & \multirow{2}{*}{ Means } & \multirow{2}{*}{ RII } & \multirow{2}{*}{ Rank } \\
\hline & & 1 & 2 & 3 & 4 & 5 & & & & \\
\hline 1. & Legibility & 7 & 18 & 16 & 26 & 4 & 71 & 3.03 & 0.61 & 3 \\
\hline 2. & Accessibility & 9 & 32 & 7 & 21 & 2 & 71 & 2.65 & 0.53 & 4 \\
\hline 3. & Continuity & 4 & 16 & 6 & 28 & 17 & 71 & 3.54 & 0.71 & 1 \\
\hline 4. & Consistency & 6 & 20 & 13 & 25 & 7 & 71 & 3.10 & 0.62 & 2 \\
\hline
\end{tabular}

Table 5 Improving the current site progress record keeping practice.

\begin{tabular}{|c|l|c|c|c|}
\hline S/No & \multicolumn{1}{|c|}{ Issues } & Options & Responses (\%) & Total (\%) \\
\hline \multirow{2}{*}{1.} & There is need to improve the current site & YES & 95 & \\
\cline { 3 - 4 } & progress Record Keeping Practice & NO & 5 & \\
\hline \multirow{2}{*}{2.} & \multirow{2}{*}{$\begin{array}{l}\text { Most favoured means of achieving the } \\
\text { improvement }\end{array}$} & $\begin{array}{l}\text { Regular inspection of document by } \\
\text { supervisors }\end{array}$ & 38 & \\
\cline { 3 - 4 } & & In - house training of site staff & 27 & 95 \\
\hline
\end{tabular}


by consistency with 0.62 and legibility with 0.61 . Accessibility of the records has the lowest rating of 0.53 and is therefore the problem least encountered in the present approach to site record keeping.

\section{Conclusions and Recommendation}

The five site progress documents (minutes of progress meetings, day work sheets and agreed records, photographs, weekly progress records, and personal site diaries) are widely used in Abuja and have very high relative importance rating except for personnel site diaries which have only a high importance rating.

There are very good reasons for keeping the records, prominent among which are: control of on-going work, data for estimating future work and terms of contact requirements. Although the current record keeping practices are assessed satisfactory there is still room for improvement. The challenges in the current practice are consistent with those identified in exiting literature and are: continuity, consistency, legibility and accessibility, in descending order of frequency of occurrence.

\subsection{Recommendations}

(1) Diligence should be exercised in the building up and keeping of all five documents that constitute site progress records, especially for the minutes of progress meetings, weekly progress records and photographs.

(2) Improvement on the current site progress record keeping practice should be sought more through improving the continuity, consistency and legibility of the documents.

(3) Computer based record keeping, regular inspection of the documents by supervisors and in-house training of personnel should be employed for improving the current practice.

\section{References}

[1] S. Ajamlekoko, Construction contract conditions and documentation "seminar on planning and execution of capital project in an emerging democracy", Nigeria Institute of Building April, 2002, pp. 1-15.
[2] S. Scott and S. Assadi, Delay claims in UK contracts, Journal of Construction Engineering and Management 123 (3) (1997) 238-244.

[3] S. Kartarm, Generic methodology for enlisting delay claims, Journal of Construction Engineering and Management 125 (6) (1999) 409-449.

[4] E. A. Nesiama, An assessment of construction supervisors' site records as a monitoring tool for public building projects, Unpublished M.Sc thesis Department of Building, Ahmadu Bello University Zaria, 2009, pp. 8-36.

[5] J. Sommerville, N. Craig and M. Mc Carmey, Document transfer and communication between distinct construction professionals, in: The Construction and building research conference of the Royal Institute of charted survey org, 2004, p. 10.

[6] Z. A. Memom, M. A. Majid and M. Mustafar, Digitalizing construction monitoring (DCM): An overview of Malaysian Construction industry and proposing prototype software', in: Asia-Pacific Structural Engineering and Construction Conference, 2006, pp. D-15- 27.

[7] S. Scott and S. Assadi, A survey of the site records kept by construction supervisors, Construction Management and Economics 17 (1999) 375-382.

[8] Y. Chen and J. Kamara, The mechanism of information communication on construction sites, Forum E journal 8 (2008) 1-32.

[9] S. Haunt, The lesson: Keep detailed records arabian business, available online at: http/www.arabianbusiness.com.htm, accessed on 22 October, 2007.

[10] K. K. Chikara, Construction Project Management, Planning Scheduling and Controlling, Tata McGraw Hill Publishing Company Ltd, New Delhi, 2008, pp. 250-275.

[11] R. M. Wildman, Construction claims identification, Communication and Record Keeping "TUNS/Revey seminar", 1990.

[12] S. Scott and S. Assadi, Toward an electronic site diary, Construction Information Digital Library 78 (1998) 349-358.

[13] H. Tarek, E. Emod and Z. Kehni, Keeping better site records using intelligent bar-charts, Journal of Construction Engineering and Management (2008) 513 -514 .

[14] S. Bowden, A. Thope and A. Baldwin, Usability testing of hand held computer on a construction site, Construction Informatics Library, available online at: http/fitescix.net/paperw78-2003-47.content, accessed 15 January, 2008. 